\title{
Care or custody? Ethical dilemmas in forensic psychiatry
}

Gwen Adshead Broadmoor Hospital, Crowthorne, Berkshire

Ethical dilemmas in forensic psychiatry have not, on the whole, been exposed to the same degree of scrutiny as other medical topics in the medical ethical literature. In this editorial, I will hope to show that forensic psychiatric practice raises many ethical dilemmas; not only practical, but also conceptual. Indeed the level of public debate following the publication of the Fallon report ${ }^{1}$ and new proposals for preventive detention of dangerous people ${ }^{2}$ suggest that these dilemmas also belong in the political sphere. Renewed attention to this area is therefore timely.

In this editorial, I shall provide a brief overview of the many ethical dilemmas that arise in relation to the practice of forensic psychiatry. I shall use the four principles plus scope approach ${ }^{3}$ for my analysis. I will invert the usual discussion order; reflecting perhaps the relative importance of the different principles in forensic psychiatry.

\section{Respect for justice}

Forensic psychiatry represents the interface of two worlds which identify and regulate deviance ie medicine and the law. Many ethical-conceptual issues in relation to psychiatry still need elucidation. For example, what counts as a mental illness, and how does mental illness excuse responsibility for criminal actions? This question is particularly difficult to answer in relation to personality disorder, and its sister concept, psychopathy.

Respect for justice usually requires that we treat similar people in similar ways. However, forensic patients are vulnerable to exploitation and injustice. For example, mentally ill offenders are detained longer in secure settings than their counterparts who have committed exactly the same offence, but do not have a mental disorder. ${ }^{4}$ Political pressures (especially if the patient has a high media profile), and concern for victim's feelings may influence release decisions. This may do justice to the victims of violence, but at the expense of the offender patient's welfare; so that the patient's claim to justice is set against another's claim in an adversarial way. It is arguable that because forensic patients are vulnerable, there is an increased duty of care on professionals to respect their claims to justice.

Finally, forensic clinicians often face dilemmas about the safety of convictions, and the proper atti- tude towards the findings of criminal courts. It may seem obvious that the clinician should accept any criminal conviction as a fact about the patient. But miscarriages of justice do occur, resulting in false convictions. Consider, for example, the case of a young man charged with rape, who denied this offence and was convicted on DNA evidence. He developed a mental illness and received a hospital disposal instead of a prison sentence. However, he continues to deny the offence, and disputes the evidence against him. Current mental health legislation makes it impossible for him to be discharged, but there appears to be no problem to treat. Consider also the case of a man who was convicted of a murder and sent to prison, from where he was transferred to a Special Hospital when he became mentally ill. He constantly denied his offence; it later transpired that he was innocent, and he was released.

In both these cases, forensic mental health professionals are faced with the reality of an established conviction in a criminal court. To challenge that conviction, they must set up an alternative clinical "court", which contradicts the usual rules of justice. However, it might be argued that those who owed such patients a duty of care also had a duty to take their protestations of innocence seriously.

\section{Respect for autonomy}

Like other mental health professionals, forensic practitioners face difficulties in relation to the autonomy of their patients. Some of these difficulties are the familiar ones relating to legal coercion of people with mental illnesses, and the impairment of autonomy by mental illness. In such cases, restrictions of autonomy may be justified with respect to the patient's own welfare. However, in forensic settings, as in prison, other people's welfare can also become a justification for restrictions on autonomy; I shall return to this under the heading of non-maleficence.

The views of the patients themselves about their treatment generally speaking carry little weight. Decisions about treatment and discharge tend to be influenced and often made by third parties. The extent to which patients in coercive settings can consent to interventions is also a matter of debate; 
when does consent become mere assent? This question is particularly acute in relation to compliance with medication, because increased liberty may be dependent on the patient's agreement to take medication.

There is also a further question about the autonomy of forensic patients to make choices which are uncomfortable or unattractive to others. Conventional notions of respect for autonomy suggest that patients should generally be able to make decisions for themselves, consistent with their own view of the world and themselves. In forensic settings, it may not be possible to tolerate world views which are violent or oppressive or even simply objectionable to others; especially if it is thought that those views have contributed to the commission of violence. A banal example relates to videos; should people with histories of violence be allowed to watch Four weddings and a Funeral, but not Reservoir Dogs? Or (as in one case) should a patient be allowed to watch a cinematic (and violent) version of his own life?

\section{Non-maleficence}

There are many concerns within forensic psychiatry about not doing harm to patients. First, the pharmacological management of violence makes use of sedating drugs which decrease the risk of violence, but may increase a risk to the health of the patient. Second, it is not clear who should be judging the harm suffered; patients may experience the use of seclusion or other types of behaviour modification as unjustified harm, as opposed to staff who perceive it as justified. In usual clinical settings, the patient's view should prevail. Furthermore, it may also be argued that the loss of physical autonomy caused by drugs or seclusion is harmful.

A crucial (and contemporary) issue relates to the question of preventive detention, ie detention of patients who might be dangerous in the future for the safety and/or the benefit of others. Detention on the grounds only of public safety is commonplace in criminal justice settings; but makes little sense in health settings where the patient's welfare is morally and legally the object of the professional duty of care. The ethical argument against preventive detention rests on the claim that doctors do these detained patients both a wrong, and a harm. The justification for preventive detention then seems to rest on the notion that harm to these offender patients is preferable to harm to "innocent" people. Other related dilemmas include the question of how far any social group should infringe the liberty of members in order to protect its members; and the validity and reliability of risk assessments as a justification for measures which do restrict liberty.

\section{Beneficence}

In forensic psychiatry there may be uncertainty about what "clinical benefit" means, who should decide, and how. A significant ethical conceptual difficulty lies in the question of whether, or to what extent, "behaving better" is a benefit of treatment.
This conceptual question contradicts notions of the moral neutrality of medicine, and raises again, but in a different setting, the questions raised by Szasz about psychiatry as a covert measure of social control..$^{5}$ Arguably, forensic psychiatry is an overt agent of social control, if the main benefit of any treatment is conformity with the law. Many forensic patients do suffer from illnesses, for which they need help and relief, even if their behaviour does not change. However, treatments that make offender patients feel better, but which don't reduce their offending behaviour, may not be welcomed by those who understand the primary duty of forensic psychiatrists to be making people safer.

This question of whose benefit should count has an interesting twist in relation to expense. If new (but expensive) anti-psychotic medication significantly reduced offending behaviour, then surely it would be justifiable to allocate resources for that medication. Patients who made a good response to such expensive medication would not only be less dangerous, but also more manageable, perhaps in less expensive settings. Thus a fairly considerable expense (prescribing anti-psychotic medication) would result long term in considerable savings, both to the patient and to society. However, this kind of resource-allocation, cost-benefit analysis is rarely done in relation to forensic psychiatry. In practice, such drugs are very expensive and tend to be restricted; mentally disordered offender patients who might benefit from them end up on cheaper, standard and less effective medications, and detained indefinitely in high security hospitals, which they do not like, and find stigmatising. Of course, such hospitals do provide employment for large numbers of people, and a place for society to hide away unwanted and unattractive people. Expensive drugs that significantly reduce violent behaviour and thus reduced secure hospital populations might therefore also have other social impacts.

\section{Scope}

The crucial issue of scope relates to the duties of forensic psychiatrists to third parties. There needs to be more discussion about the nature and scope of duties to third parties; especially as they impact on psychiatrists' duty of care to patients. There is a well established tradition in medicine of doctors having duties to third parties; for example, in public health. But in public health settings, there is no single patient (or patients) known to the doctor, whose interests will be significantly harmed if the doctor pays attention to the claims of third parties. Furthermore, what is being mooted for forensic psychiatrists is a specific professional duty to protect the public. This would be part of the psychiatrist's duty of care; it would go beyond any normal duty of a citizen to prevent violence, and would resemble the duties of law enforcement agents.

It may be argued (after the well-known case of Tarasoff ${ }^{6}$ ) that there is a duty to warn and protect identifiable third parties. Increasing information 
about risk would justify a greater claim on the part of those third parties. But this position is rather different from that which argues that psychiatrists have a primary duty of care to protect the public from harm from offender patients. At present, if an ordinary citizen makes threats to kill someone, the police may or may not act depending on whether they think the citizen has actually breached the relevant statute; however, if an individual with a history of mental illness makes a threat to kill, then it is sometimes claimed that psychiatrists should immediately detain that person indefinitely against his or her will.

I would argue that forensic psychiatrists do have duties to third parties in certain circumstances, but do not have an overall primary duty to protect the public. If, however, (after public and professional debate) it was determined that there was a primary duty, specific to forensic psychiatrists, to protect the public, perhaps arising from their specialist knowledge, then this change should be made explicit and forensic psychiatrists should become like other professional groups whose duty is to protect the public. Extra training would be required to make forensic psychiatrists conversant with relevant types of law; their new duties should be explicitly stated in their contracts, and relevant advice should explicitly be given to patients.

\section{Conclusion}

It is hard not to perceive that the interests of mentally abnormal offenders come at the bottom of almost any list of priorities; partly because such patients are vulnerable and can be exploited, but also because they are "guilty" individuals, and can thus claim less moral or legal protection. Some of the ethical dilemmas in managing patients in foren- sic psychiatry services may arise from the fact that our patients are highly stigmatised, and often deemed as "valueless" by the rest of society.

I hope that I have demonstrated that complex ethical dilemmas arise daily in the management of patients by forensic psychiatric services. I have not even touched on more conceptual questions, such as how mental illness might excuse; or related legal issues, such as the ethical dilemmas that arise in relation to psychiatrists giving expert evidence. Our American counterparts face starker dilemmas in relation to giving testimony in cases involving the death penalty. Many of the questions raised have complex profound philosophical concepts and dilemmas at their heart; I look forward to future articles in the journal, in which philosophical analysis may help to elucidate profound and painful problems in forensic psychiatry.

Gwen Adshead, MA(Medical Law and Ethics), is a Consultant and Honorary Senior Lecturer in Forensic Psychotherapy at Broadmoor Hospital, Crowthorne, Berkshire and St George's Hospital, London.

\section{References}

1 Fallon P, Bluglass R, Edwards B, Daniels G. Report of the Committee of Inquiry into the Personality Disorder Unit, Ashworth Special Hospital, vol I and II. London: The Stationery Office, 1999: $\mathrm{Cm} 41945$.

2 Home Office/Department of Health. Managing dangerous people with severe personality disorder: proposals for policy development. London: Home Office/Department of Health, 1999 July.

3 Gillon R. Medical ethics: four principles plus attention to scope. British Medical fournal 1994;309:184-8.

4 Dell S, Robertson G. Sentenced to hospital [Maudsley monograph]. Oxford: Oxford University Press, 1988.

5 Szasz T. Law, liberty \& psychiatry. London: Routledge \& Kegan Paul, 1974 .

6 Taul, 1974 . 6 Tarasoff v Regents of University of California. Supreme Court P.2d 334 . 